\title{
Structure of amorphous silica-hafnia and silica-zirconia thin-film materials: the role of a metastable equilibrium state in non-glass- forming oxide systems
}

\author{
Namjun Kim ${ }^{\mathrm{a},{ }^{*}}$, Riccardo Bassiri ${ }^{\mathrm{b}}$, Martin M. Fejer ${ }^{\mathrm{b}}$, Jonathan F. Stebbins ${ }^{\mathrm{a}}$ \\ ${ }^{a}$ Department of Geological and Environmental Sciences, \\ Stanford University, Stanford, CA 94305 \\ ${ }^{\mathrm{b}}$ E.L. Ginzton Laboratory, Stanford University, Stanford, CA 94305
}

August 20, 2015, revised version for J. Non-Crystalline Solids

Keywords: nuclear magnetic resonance, silica-hafnia, silica-zirconia, LIGO, optical multilayer coating

* Correspondence should be addressed to Jonathan Stebbins

Tel: 1-650-723-1140

E-mail address: stebbins@stanford.edu 


\begin{abstract}
Amorphous heavy metal oxide thin films have important technological applications, including multi-layer mirror coatings in instruments such as the Laser Interferometric Gravitational Wave Observatory (LIGO). However, the structures of these materials are much less well-known than those of conventional glass-forming oxides. For example, it has not been clear whether films deposited by methods such as ion beam sputtering (IBS) ever pass through a state of local (metastable) thermodynamic equilibrium, and hence could be amenable to modeling by thermodynamic approaches long explored in glass-forming liquid systems. We present new ${ }^{17} \mathrm{O}$ and ${ }^{29}$ Si NMR data on IBS films and sol-gel equivalents in the silica-hafnia and silica-zirconia binary systems. Similar distributions of local structural groups are obtained by different synthesis routes, suggesting that indeed a transient, possibly liquid-like metastable state is reached during film formation. All oxygen species are well-resolved in the spectra and can be readily quantified. Their concentrations are indeed well-predicted by a simple thermodynamic treatment, similar to that applied for decades to binary metal oxide-silica liquids, based on the reaction of bridging oxygens with added "free” metal oxide ions to form non-bridging oxygens.
\end{abstract}

\title{
1. Introduction
}

Amorphous, heavy metal oxide thin films are of widespread interest as high refractive index coatings in multi-layer mirrors in optical systems including LIGO, the Laser Interferometric Gravitational Wave Observatory [1]. Either as single (e.g. $\mathrm{Ta}_{2} \mathrm{O}_{5}$ ) or mixed (e.g. $\mathrm{TiO}_{2}-\mathrm{Ta}_{2} \mathrm{O}_{5}, \mathrm{SiO}_{2}-\mathrm{HfO}_{2}$ ) oxides, generally deposited by various sputtering methods, these can be single-phase, crystal-free, and can have extremely good optical properties. Nonetheless, desired 
improvements in LIGO mirror coating performance, such as reduction in Brownian thermal noise that can limit detector sensitivity, have lead to an ongoing international research effort on the structures of such materials and on understanding property-structure relationships at a more fundamental level [2-10] Related materials, such as amorphous $\mathrm{SiO}_{2}-\mathrm{HfO}_{2}$ and $\mathrm{SiO}_{2}-\mathrm{ZrO}_{2}$ with higher silica contents, have important applications as high-k dielectric layers in microelectronics and have been extensively investigated by X-ray and NMR methods [11-17].

In general, amorphous heavy metal oxides cannot be formed as glasses quenched from high temperature oxide melts, as these contain low contents of "network-forming” cations, and hence are very "fragile” [18], often have wide liquid-liquid immiscibility fields [19], and in some cases (e.g. $\mathrm{Ta}_{2} \mathrm{O}_{5}$ ) may not even exist as stoichiometric, stable liquids due to oxygen loss at their very high melting points. Some of these compositions can also be made in amorphous form by low-temperature, sol-gel routes. A number of non-glass-forming liquids of lighter metal oxides, most notably $\mathrm{Al}_{2} \mathrm{O}_{3}$, can also be formed in the amorphous state by thin film deposition methods, and also have important applications in optical coatings and other technologies [20-23].

Unlike thin-film oxides that can also be formed as bulk glasses by normal quenching methods (e.g. silica and silicates), the structures of thin-film amorphous heavy metal oxides are much less studied, leaving wide gaps in our ability to predict and optimize their properties as functions of composition and thermal history. Improvements in spectroscopic methods, notably the ability to collect high-quality NMR and X-ray spectra on relatively small quantities of sputter-deposited materials, have recently allowed important steps forward for materials such as tantala, tantala-titania [4-6], and alumina, both in pure form [20-22] and doped with $\mathrm{ZnO}$ [23]. Nonetheless, important fundamental questions remain about such materials and their relationships to "normal" melt-quenched glasses. Are thin-film amorphous oxides far out of 
equilibrium at all stages of their formation, or do they somehow pass through an equilibrium (most likely metastable) state, potentially very rapidly, during deposition or on subsequent annealing? If that state is "liquid-like," with rapid enough bond breaking and re-formation to allow full relaxation of at least the short-range structure, then subsequent quenching to an amorphous solid could imply a dynamical transition similar to that of more conventional glasses. Whether or not such a transition can be directly observed remains an open question. However, if even a short-lived equilibrium state governs the structures and properties of some thin film oxide materials, then thermodynamic modeling becomes more credible, and could play an important role in tailoring their properties to applications, as long has been the case for melt-quenched glasses. Based on detailed new data on the distributions of oxygen and silicon species from NMR spectroscopy on ion-beam sputtered and sol-gel formed, amorphous silica-hafnia and silicazirconia materials, we suggest here that this is indeed the case.

\section{Experimental}

Silica-hafnia samples with nominally 12 , 30, and 50 mole $\% \mathrm{SiO}_{2}$, as well as pure hafnia and pure silica, were prepared by sol-gel method using tetraethyl orthosilicate (TEOS) and hafnium $t$-butoxide $\left(\mathrm{Hf}(t \text {-OBu })_{4}\right)$, in ethanol-water mixtures with $\mathrm{HCl}$ as an acid catalyst. Because the hydrolysis of TEOS is relatively slow, the TEOS was hydrolyzed first before $\operatorname{Hf}(t$ $\mathrm{OBu})_{4}$ was added. The ethanol-water mixture was prepared from ethanol and a $0.1 \mathrm{M} \mathrm{HCl}$ aqueous solution in a 1:1 molar ratio, followed by addition of TEOS to bring the ratio of TEOS: water: ethanol to 1:1:1. After the solution was stirred for 2 hours, an appropriate amount of $\operatorname{Hf}(t-$ $\mathrm{OBu}_{4}$ and water (in 1:2 ratio) was added. After stirring, the samples were aged for about one week and dried for several days in air. Separate portions of the resulting powders were further 
dried at $300{ }^{\circ} \mathrm{C}$ and $600{ }^{\circ} \mathrm{C}$ for another day. For the ${ }^{17} \mathrm{O}$ NMR experiments, the unheated samples were dried at $600^{\circ} \mathrm{C}$ for 2 hours in air and then heated in open gold tubes contained in sealed silica glass tubes with ${ }^{17} \mathrm{O}$ enriched $\mathrm{O}_{2}$ gas $(70 \%)$ at $600^{\circ} \mathrm{C}$ for 1 day, as done previously for tantala IBS films [5, 6].

A $0.5 \mu$ m thick amorphous $\mathrm{SiO}_{2}-\mathrm{HfO}_{2}$ film, nominally with 30 mole $\% \mathrm{SiO}_{2}$, and a comparable $\mathrm{SiO}_{2}-\mathrm{ZrO}_{2}$ film (nominally $25 \%$ mole $\% \mathrm{SiO}_{2}$ ), were deposited using ion beam sputtering (IBS) by MLD Technologies (Mountain View, CA) on $2.54 \mathrm{~cm}$ diameter $\mathrm{NaCl}$ disk substrates using $\mathrm{SiO}_{2}$ and $\mathrm{Hf}$ or $\mathrm{Zr}$ metal targets with $\mathrm{O}_{2}$ gas. The film samples delaminated from the $\mathrm{NaCl}$ disks after the deposition and exposure to air. These were exchanged with ${ }^{17} \mathrm{O}_{2}$ gas as for the sol-gel materials. In a previous study of $\mathrm{IBS}_{\mathrm{Ta}_{2} \mathrm{O}_{5}}[6]$, we showed that the oxygen speciation in such post-deposition exchanged films was the same as for a film initially deposited with ${ }^{17} \mathrm{O}_{2}$ gas as the sole oxygen source, demonstrating the lack of preferential exchange rates among different kinds of sites.

As discussed in section 3.5 below, the compositions of the sol-gel and IBS materials can be estimated from analysis of the ${ }^{17} \mathrm{O}$ NMR spectra. For the sol-gel materials, these agree relatively well with the nominal values, but are more different for the films. For consistency, the calculated values are used in figure labels and subsequent calculations.

X-ray diffraction (XRD) measurements were made on sol-gel prepared samples with different silica contents and annealing temperatures using a Philips X'Pert Pro diffractometer with $\mathrm{Cu} \mathrm{K} \alpha$ radiation for the $2 \theta$ range of $20-70^{\circ}$ at a scan rate of $0.05 \%$.

${ }^{29}$ Si MAS NMR experiments were carried out with a Varian Unity/Inova 600 spectrometer (14.1 T) at a Larmor frequency of $119.13 \mathrm{MHz}$ using a $3.2 \mathrm{~mm}$ Varian/Chemagnetics “T3” type MAS probe. Spectra were obtained using a single pulse 
experiment with a typical pulse width of approximately $0.7 \mu \mathrm{s}$ ( $30^{\circ}$ radiofrequency tip angle) and spinning speeds of $20 \mathrm{kHz}$. Chemical shifts were externally referenced to TMS

(tetramethylsilane) at $0 \mathrm{ppm}$. Pulse delays of 0.1 to $5 \mathrm{~s}$ were used for thin-film samples, which relaxed relatively rapidly. The sol-gel powders had much slower relaxation: 1 to 60 s pulse delays were used for the un-annealed samples, and 1 s to 5 min delays were required for the samples annealed at $600^{\circ} \mathrm{C}$. Spectra with different pulse delays were compared in order to detect differential relaxation among different silicate species: none was observed. For the un-annealed and annealed IBS film, the spin-lattice relaxation was measured by the inversion-recovery method.

${ }^{17} \mathrm{O}$ NMR data were collected with a Varian Unity/Inova 600 (14.1 T) spectrometer at a Larmor frequency of 81.29 MHz. Single pulse spectra were acquired using a $3.2 \mathrm{~mm}$ Varian/Chemagnetics “T3” type MAS probes with spinning speeds of about $20 \mathrm{kHz}$. A small pulse width was used to ensure that the intensities are quantitative for ${ }^{17} \mathrm{O}$, a quadrupolar nuclide. A typical pulse width was $0.3 \mu$ s, equivalent to a $\pi / 18$ tip angle for the liquid standard. Peak positions were externally referenced to ${ }^{17} \mathrm{O}$-enriched water at $0 \mathrm{ppm}$. As for the ${ }^{29} \mathrm{Si}$ data, no differential relaxation was observed among peaks for different oxygen species.

\section{Results}

\subsection{X-Ray diffraction}

XRD was carried out for the sol-gel samples annealed at $300^{\circ} \mathrm{C}$ and $600^{\circ} \mathrm{C}$. The samples heated at $300^{\circ} \mathrm{C}$ all remained X-ray amorphous. The pure hafnia sample heated at $600^{\circ} \mathrm{C}$ crystallized to monoclinic m-HfO 2 (Fig. 1) while the $12 \%$ silica-hafnia sample from this temperature showed low, broad diffraction peaks for the same phase. For the 31 and $54 \%$ silica 
samples annealed at $600{ }^{\circ} \mathrm{C}$, however, no crystallization was detected by XRD, suggesting a compositional range where silica stabilization of the amorphous phase is effective. No XRD data were collected for the thin film samples, but ${ }^{17} \mathrm{O}$ NMR results (see below) show that both unannealed and annealed samples remained amorphous.

\section{$3.2{ }^{29} \mathrm{Si}$ MAS NMR of sol-gel samples}

For the silica-hafnia sol-gel samples, ${ }^{29} \mathrm{Si}$ MAS NMR spectra were collected prior to heating and after annealing at $600{ }^{\circ} \mathrm{C}$ during ${ }^{17} \mathrm{O}$ exchange (Fig. 2). These spectra are relatively noisy because of long spin-lattice relaxation times, particularly after removal of $\mathrm{OH}$ groups during annealing. The centers of gravity of the peaks are given in Table 1. Only the unheated, pure silica sample shows resolved peaks, as is normal for typical, OH-rich silica "gel” [24]. The three peaks at -92, -102, and -111 ppm are readily assigned to sites with 2, 3 and 4 bridging oxygens, denoted $\mathrm{Q}^{2}, \mathrm{Q}^{3}$, and $\mathrm{Q}^{4}$. Given differences between the electronic effects of Si-O-H vs. Si-O-Hf bonding, the first two of these are likely to have somewhat higher (less negative) chemical shifts than comparable species in the silica-hafnia materials, but the $\mathrm{Q}^{4}$ groups should be in similar positions in both. The dehydrated amorphous pure silica sample $\left(600{ }^{\circ} \mathrm{C}\right)$ has a single, broader peak in this same region of the spectrum. The likely location of $\mathrm{Q}^{0}$ silicons is suggested by the known chemical shift of zircon $\left(\mathrm{ZrSiO}_{4}[24]\right)$ at $-81.6 \mathrm{ppm}: \mathrm{Hf}^{4+}$ and $\mathrm{Zr}^{4+}$ are expected to have similar effects on ${ }^{29} \mathrm{Si}$ shifts, given their identical valence and nearly identical cationic radii $\left(\mathrm{Hf}^{4+}: 0.83\right.$ or $0.71 \AA$ in 8 or 6 coordination, $\mathrm{Zr}^{4+}: 0.84$ or $0.72 \AA$ respectively) [25].

The center of gravity for the $12 \%$ silica sample corresponds to that of $\mathrm{Q}^{0}$ species in crystalline zircon (or hafnon), but is much broader than expected for a crystalline material. The asymmetry of the peak towards lower chemical shifts suggests the presence of a minor 
percentage of $\mathrm{Q}^{1}$ groups. The centers of gravity for the 31 and $54 \%$ silica samples move down in frequency as expected if there are higher proportions of silicon sites with more bridging oxygens, but none of the silica-hafnia sol gel samples have spectra with significant (more than a few \%) intensity in the $\mathrm{Q}^{4}$ region. This indicates that little or none of the Si occurs in domains of pure silica. Spectra of the as-formed, un-annealed silica-hafnia sol gels (not shown) resembled those of the annealed materials, but were generally shifted 2-5 ppm to higher frequency, presumably primarily by the presence of some Si-OH groups.

\section{$3.3^{29} \mathrm{Si}$ MAS NMR of IBS films}

${ }^{29} \mathrm{Si}$ MAS NMR spectra were collected for the nominally $30 \% \mathrm{SiO}_{2}-\mathrm{HfO}_{2}$ film (actual composition is probably close to $21 \%$, see Table 2 and discussion of ${ }^{17} \mathrm{O}$ NMR data below), unannealed and annealed at $600^{\circ} \mathrm{C}$ for ${ }^{17} \mathrm{O}$ enrichment (Fig. 3). Signal-to-noise ratios for the thinfilm samples were higher than for the sol-gel samples, because of the much shorter spinrelaxation times of the former (see below). The peak positions and shapes are similar to the solgel samples with low silica contents. The centers of gravity are $-86 \mathrm{ppm}$, and $-87 \mathrm{ppm}$ for the unannealed and annealed films, respectively, the latter between those for the $12 \%$ and $31 \%$ sol-gel samples as expected. In this case the small change in peak position on heating cannot be simply explained by the removal of water and organic components, and may suggest instead a slight shift in bond angles or distances due to minor structural or density relaxation.

The ${ }^{29} \mathrm{Si}$ spectrum (Fig. 3) for the unannealed silica-hafnia thin film sample shows in addition a small, broad peak centered at $-125 \mathrm{ppm}$, comprising about $2 \pm 1 \%$ of the total intensity, and falling outside of the known chemical shift range for $\mathrm{SiO}_{4}$ groups [24]. This unusual resonance is greatly reduced in intensity by annealing. However, its relative peak area does not 
change with pulse delay (0.02 vs. $1 \mathrm{~s})$, indicating a relaxation rate similar to that of the main peak; its position does not change with the minor temperature shifts (ca. $20{ }^{\circ} \mathrm{C}$ ) induced by changing the spinning speed (and thus air frictional heating) from 20 to $10 \mathrm{kHz}$ [26]. Both observations show that this feature is not shifted by the effects of paramagnetic ions [27], which are suspected to be present in these samples due to a slight oxygen deficit (see next section). Instead, its most likely origin is the presence of a small concentration of $\mathrm{SiO}_{5}$ groups, which have been detected in a few ambient and high pressure melt-quenched glasses and are known to have resonances in the range from about -125 to -150 ppm [28-33]. As relatively high-energy “defect” species, it is not surprising that these are mostly eliminated by annealing.

The silica-zirconia film has a considerably higher $\mathrm{SiO}_{2}$ content of $41 \%$, as calculated from the observed oxygen speciation (Table 2), and its ${ }^{29} \mathrm{Si}$ spectrum is thus shifted to lower frequencies. Given the lack of resolution among the components for the various $\mathrm{Q}^{\mathrm{n}}$ species, we have not attempted to determine this aspect of the structure in detail, but clearly the material must contain higher proportions of groups such as $\mathrm{Q}^{1}, \mathrm{Q}^{2}, \mathrm{Q}^{3}$, and even $\mathrm{Q}^{4}$ than the lower-silica $\mathrm{SiO}_{2}-\mathrm{HfO}_{2}$ film. Annealing of the $\mathrm{SiO}_{2}-\mathrm{ZrO}_{2}$ film again shifts the peak to somewhat lower frequency, again suggesting some shift in bond angles and possibly of the distribution of $\mathrm{Q}^{\mathrm{n}}$ groups.

\section{$3.4{ }^{29} \mathrm{Si}$ spin-lattice relaxation}

For the un-annealed sol-gel samples, full relaxation of the NMR signal required a pulse delay of more than a minute; after annealing at $600{ }^{\circ} \mathrm{C}$ even 5 minute pulse delays did not give full relaxation. It is likely that $\mathrm{OH}$ groups helped to speed relaxation in the former. 
In contrast, the spectra for the unannealed silica-hafnia film sample appeared to be fully relaxed with pulse delays of a fraction of $1 \mathrm{~s}$. Annealing at $600{ }^{\circ} \mathrm{C}$ in $\mathrm{O}_{2}$ gas during isotopic enrichment slowed relaxation significantly. Spin lattice relaxation times for the film samples were measured using saturation-recovery experiments. The relaxation curves are shown in Figure 4. Data were best fit by stretched exponential functions for the signal intensity I, relative to the fully relaxed value $\mathrm{I}_{0}$, as a function of relaxation delay time $\tau$, with

$$
\mathrm{I} / \mathrm{I}_{0}=1-\exp \left[-\left(\tau / \mathrm{T}^{\prime}\right)^{\beta}\right]
$$

Results for the unannealed film give T' and $\beta$ of $0.04 \mathrm{~s}$ and 0.6 , and for the annealed film $0.23 \mathrm{~s}$ and 0.76 . $\beta$ values between 0.5 and 1 are typical in systems where an important component of the relaxation mechanism is through-space dipolar coupling between nuclear spins and the electronic spins of paramagnetic impurities [34, 35]. Given that there are no sources of $\mathrm{H}_{2} \mathrm{O}$ or $\mathrm{H}$ in the IBS deposition system, the likely cause of the enhanced relaxation in the film samples is the presence of a fraction of a percent of paramagnetic Hf ions with a valence less than 4 (and hence unpaired electronic spins), related to a slight initial oxygen deficit, as previously described for IBS $\mathrm{Ta}_{2} \mathrm{O}_{5}$ films [6]. Re-oxidation during annealing removes most, but apparently not all, such defects. The fortuitous presence of such defects actually considerably enhances the quality of the spectra attainable for such materials.

\section{$3.5{ }^{17} \mathrm{O} M A S N M R$}

The $100 \% \mathrm{HfO}_{2}$ sol-gel sample crystallized completely on annealing at $600{ }^{\circ} \mathrm{C}$, to form the monoclinic phase. Its ${ }^{17} \mathrm{O}$ NMR spectra (Fig. 5) contains two very narrow resonances at 338 and $270 \mathrm{ppm}$, with equal peak areas and assignable to oxygen with 3 and $4 \mathrm{Hf}$ first neighbors respectively, consistent with published data for this phase [11]. 
The spectra for the annealed, ${ }^{17} \mathrm{O}$-enriched silica-hafnia sol-gel and IBS film samples all contain four broader peaks centered around 350, 260, 170, and 30 ppm (Fig. 5). None shows obvious quadrupolar splitting. The first two of these can readily be assigned to sites resembling those in the crystalline hafnia, denoted here as OHf3 and OHf4. Indeed, the 12\% silica sample shows narrow, crystal-like peaks in these regions on top of broader, amorphous-phase peaks, consistent with a small amount of the crystal, as also observed by XRD (Fig. 1). These sharp features are also just detectable in the $31 \%$ sol-gel sample, suggesting in this case that the NMR is more sensitive than routine XRD for the detection of crystallinity. NMR peak areas indicate about $11 \mathrm{~mol} \%$ and $1 \mathrm{~mol} \%$ of crystalline $\mathrm{m}-\mathrm{HfO}_{2}$ in the two materials (percentages of total ${ }^{17} \mathrm{O}$ signal). No such sharp peaks were observed in the IBS film samples, demonstrating their amorphous character.

The ${ }^{17} \mathrm{O}$ NMR peak at about $30 \mathrm{ppm}$ is consistent with bridging oxygens (Si-O-Si) in silica and other silicates, as observed in numerous previous studies [24, 36, 37]. The remaining peak at about $170 \mathrm{ppm}$ thus must be due to the oxygen coordinated by both silicon and hafnium, and appears in a chemical shift range for "non-bridging" oxygens bonded to one $\mathrm{Si}$ and one or more high field strength "modifier" cations. Its position is close to that reported for crystalline $\mathrm{ZrSiO}_{4}$ at $160 \mathrm{ppm}$ [24]. Based on the structure of the latter mineral and simple bond valence considerations, we assume that these oxygens have $2 \mathrm{Hf}$ first neighbors and label them "Si-OHf2.” The relative intensity of the Si-O-Si peak clearly increases with silica content, and those of the OHf3 and OHf4 peaks clearly decrease, consistent with these assignments.

The positions of the Si-O-Hf2 and Si-O-Si peaks change only slightly with changing silica content, but a shoulder of unknown origin at about $5 \mathrm{ppm}$ on the latter becomes less prominent for silica less than $50 \%$. The OHf4 and OHf3 peaks may shift to slightly higher 
frequencies as $\mathrm{Hf}$ content increases, possibly due to changing proportions of $\mathrm{Hf}$ and $\mathrm{Si}$ among the second cation neighbors to these oxygens, but any such effects are small.

The relatively intensities of the OHf3 and OHf4 peaks in the amorphous phases are about 3:1, in strong contrast to the $1: 1$ value for crystalline $\mathrm{m}-\mathrm{HfO}_{2}$, and requiring a lower mean coordination number for $\mathrm{Hf}^{4+}$ in the former, about 6.5 vs. 7.0 in the crystal. The peak positions for OHf3 in the amorphous phases, likely to be controlled primarily by the chemical shift for these relatively ionic bonds, are at a slightly higher in frequency than in the crystal, while those for OHf4 are slightly lower, again suggesting some differences in local structure between the crystal and these species in the amorphous phases.

The ${ }^{17} \mathrm{O}$ spectrum for the zirconia-silica IBS film (Fig. 5) is, overall, quite similar to those for the silica-hafnia materials, with the most obvious difference being the higher frequency of the peaks assignable to OZr3 and OZr4 (about 415 and $310 \mathrm{ppm}$ ), consistent with previous studies of crystalline monoclinic zirconia [24, 38]. The Si-O-Zr2 resonance is also shifted slightly up in frequency (about $10 \mathrm{ppm}$ ) relative to the corresponding Si-O-Hf2 peak.

The relative areas of the ${ }^{17} \mathrm{O}$ NMR peaks were determined by integration. To account for the overlap of spinning sidebands for the OHf3 and OHf4 peaks with the resonances for Si-OHf2 and Si-O-Si, the sideband areas as observed on the high frequency (left) side of the former two peaks were subtracted from the areas of the latter two. Other sideband intensities were of minor importance. In addition, for the 12 and $31 \%$ silica-hafnia sol-gel samples, the peak areas for the amorphous components only were estimated by subtracting those for the sharp, crystalline $\mathrm{HfO}_{2}$ peaks from the total intensities. From the relative areas of the four ${ }^{17} \mathrm{O}$ NMR peaks, the overall composition can be estimated by assuming that on average, the oxygen environments are locally charge balanced by minor variations in the Hf coordination number (7.0 in crystalline m- 
$\mathrm{HfO}_{2}$, about 6.5 in the amorphous materials). As shown in Table 2, the estimated compositions of sol-gel samples are in good agreement with nominal values, within experimental uncertainty. When the same method is applied to the spectrum for the IBS film, it gives $21 \%$ silica, which is a somewhat lower than the nominal composition of $30 \%$ silica. The spectrum for the silicazirconia IBS film was analyzed in a similar fashion, and yielded a composition of $41 \% \mathrm{SiO}_{2}$, considerably higher than the target composition of $25 \% \mathrm{SiO}_{2}$.

\section{Discussion}

\subsection{Structural speciation, homogeneity, and synthesis pathway}

The spectroscopic results presented above provide important constraints on the structures of the amorphous silica-hafnia materials, and thus on the processes by which they formed. As previously described for ${ }^{17} \mathrm{O}$ NMR spectra for amorphous $\mathrm{Ta}_{2} \mathrm{O}_{5}$ and $\mathrm{TiO}_{2}-\mathrm{Ta}_{2} \mathrm{O}_{5}[5,6]$, the silica-hafnia and silica-zirconia IBS films and sol-gel materials seem to be surprisingly similar to each other, given their very different synthesis routes. That similarity includes not only the positions and widths of the ${ }^{17} \mathrm{O}$ and ${ }^{29} \mathrm{Si}$ resonances (which are affected by details of bond angle and distance distributions), but similar proportions of oxygen and silicon species at a given composition. The high resolution among the ${ }^{17} \mathrm{O}$ resonances in the silica-hafnia materials, and accompanying accurate quantitation, gives an especially precise view of these distributions. The data for the approximately 50-50 composition provides a starting point in understanding the implications of this aspect of the structure. This composition could be nearly entirely comprised of $\mathrm{Si}-\mathrm{O}-\mathrm{Hf} 2$ linkages, if it was ordered as in crystalline $\mathrm{HfSiO}_{4}$, as suggested by at least one model of silica-zirconia coatings [39]. Instead, a distribution of oxygen species is observed that is sometimes described as "heterogeneous," with high concentrations as well of oxygens with 
only Hf first neighbors, and of oxygens with only Si neighbors. For the lower silica compositions, stoichiometry would require at least Si-O-Hf2 and O-Hf(3,4) species, but substantial amounts of Si-O-Si remain. Several possible origins for these distributions can be hypothesized.

For example, it is possible that the sol-gel materials formed initially from the aqueous phase with significant fractions of particles with nearly pure $\mathrm{SiO}_{2}$ and $\mathrm{HfO}_{2}$ compositions, with Si-O-Hf species produced by reaction at their interfaces. Simple mass balance calculations seem to rule out this scenario, as the silica particles would have to be about $1 \mathrm{~nm}$ or smaller in size for such a large number of "mixed" sites to occur at their surfaces. And, of course, it is unlikely that the same heterogeneous growth process, resulting in the same extent of mixing or reaction, would have taken place during the sputtering deposition. In contrast, it could be imagined that an initially more homogeneous phase could have undergone a process resembling liquid-liquid phase separation during annealing. At very high temperatures, $\mathrm{ZrO}_{2}-\mathrm{SiO}_{2}$ liquids do indeed have a wide two-liquid field, as expected for a binary system between silica and an oxide of a cation with a very high field strength (valence divided by the square of the cation-oxygen distance in $\AA$, $=0.9$ to 0.8 for $\mathrm{Hf}^{4+}$ or $\mathrm{Zr}^{4+}$ in six- to eight-fold coordination). When fitted with a sub-regular solution model and extrapolated far down to the temperature ranges typical of annealed silicazirconia and silica-hafnia materials of interest in dielectric coatings for microelectronics [19], the calculated solvus predicts separation into regions rich in hafnia and regions that are nearly pure silica. This prediction is analogous to well-known experimental observations of both stable and metastable two-liquid fields in many glass-forming silicate binary systems [40]. Such a process again seems to be ruled out by the close similarity of the speciation for IBS films and sol-gel materials, as the kinetically controlled processes of diffusion into separate phases, and possibly of nucleation, would seem unlikely to be the same in both systems. 
More definitively, the lack of significant intensity (less than a few \%) in the $\mathrm{Q}^{4}$ region of the ${ }^{29} \mathrm{Si}$ spectra for the lower-silica materials, especially clear for the $21 \%$ silica-hafnia film, demonstrates that any domains of pure or nearly pure silica must be of minor volumetric importance. If all of the Si-O-Si oxygens were in fact in silica-like domains containing only $\mathrm{Q}^{4}$ groups, the concentration of the $\mathrm{Q}^{4}$ among all $\mathrm{Si}$ species can be readily calculated from the observed Si-O-Si concentration and the silica content of each sample. These values are also given in Table 2. Although we have not attempted a detailed fitting of the ${ }^{29} \mathrm{Si}$ spectra (highly model-dependent for such unresolved line shapes), it is clear that these predicted $\mathrm{Q}^{4}$ proportions (for a "silica domain" model) are incompatible with the observed spectra if this species resonates in the known region for pure silica. This conclusion is further supported by the lack of differential spin-lattice relaxation in the spectra, i.e. that spectra have the same peak shapes independent of relaxation delay during acquisition. Because impurity ions that contribute to the relaxation are expected to partition out of a nearly-pure silica phase, the latter would be expected to relax more slowly, with an NMR signal that grew in with longer pulse delays. This phenomenon is well-known in systems such as nano-scale phase separated Mg silicate glasses [41], but is apparently absent in the hafnia-silica and zirconia-silica materials described here. A number of ${ }^{17} \mathrm{O}$ NMR studies have been presented on amorphous sol-gel materials in binary systems including $\mathrm{SiO}_{2}-\mathrm{ZrO}_{2}$ and $\mathrm{SiO}_{2}-\mathrm{HfO}_{2}[11-13,15,16]$, generally with considerably higher silica contents than those described here. Although somewhat less quantitative than the data presented here, these previous results show similar wide dispersion in oxygen speciation, i.e. the clear presence of some oxygen bonded only to $\mathrm{Hf}$ or to $\mathrm{Zr}$ even when not required by composition $\left(\mathrm{SiO}_{2}>50 \%\right)$. Some interpretations of these data describe some sort of "phase separation” into Hf or Zr-rich regions, apparently primarily through the observation of changes 
in EXAFS spectra indicating Hf or Zr environments with undetectable Si second cation neighbors, or in changes in the cation environment with composition. However, such results could probably also be consistent with a statistical distribution of cations in a highly disordered single-phase system, a prospect that we will examine next.

\subsection{Thermodynamics of oxygen speciation}

In models of high temperature silicate liquids, what is probably the longest-postulated, and longest studied, process can be described as a reaction between the $\mathrm{Si}-\mathrm{O}$-Si bridging oxygens (BO) in silica and the "free oxide" (FO) ion associated with an added "modifier" cation, to form non-bridging oxygens linked to a single Si and one or more modifiers:

$$
\mathrm{Si}-\mathrm{O}-\mathrm{Si}+\mathrm{O}^{2-} \Leftrightarrow 2 \mathrm{Si}^{-}
$$

or,

$$
\mathrm{BO}+\mathrm{FO} \Leftrightarrow 2 \mathrm{NBO}
$$

A simple, apparent equilibrium constant K captures much of the variation in the completeness of this reaction as a function of the composition, temperature, and modifier cation field strength and covalency, with square brackets denoting mole fractions:

$$
\mathrm{K}=[\mathrm{NBO}]^{2} /\{[\mathrm{BO}] \mathrm{x}[\mathrm{FO}]\}
$$

In the amorphous silica-hafnia materials described here, [BO] corresponds to the proportion of Si-O-Si, [NBO] to that of Si-O-Hf2, and [FO] to the sum of OHf3 and OHf4 concentrations. Although the high field strength of $\mathrm{Hf}^{4+}$ clearly places it in the range of highly charged “intermediate” cations (which bond more strongly to oxygen than conventional modifiers such as alkali and alkaline earth cations) [42], the distinction among these three types of oxygen bonding 
environments in the silica-hafnia materials is clear and unambiguous. The data for the silicazirconia film can be treated similarly.

Approximate ranges of $\mathrm{K}$ can be estimated from measured or modeled speciation data in a range of silicate systems. From studies of metal oxide-silica phase diagrams at low $\mathrm{SiO}_{2}$ contents where activities are constrained by equilibria with crystalline oxides such as $\mathrm{NiO}$ and $\mathrm{FeO}$, oxide ion activities and $\mathrm{K}$ values can be estimated in the range of about 5 to 25 at temperatures above $1600{ }^{\circ} \mathrm{C}[43,44]$. Direct spectroscopic observations of free oxide ion concentrations (as opposed to indirect estimations from thermodynamic models or from fitting spectra to estimate abundances of other structural groups) are quite limited but add useful context. For example, recent observations of $\mathrm{Si}$ and $\mathrm{O}$ speciation in $\mathrm{MgO}-\mathrm{CaO}-\mathrm{SiO} 2$ glasses near to the orthosilicate composition $\left(33.3 \% \mathrm{SiO}_{2}\right.$, below which $\mathrm{FO}$ are required by stoichiometry for divalent modifiers) suggest $\mathrm{K}$ values of about 100 to 400 at the much lower temperatures near the glass transition [45, 46]. A $\mathrm{K}$ value greater than about 400 is consistent with the nonobservation of FO by ${ }^{17} \mathrm{O}$ NMR in a $44 \% \mathrm{SiO}_{2}$ calcium silicate glass, a system in which NMR signals for FO in several crystalline materials are easily resolved [36]. Systems with "modifier" cations with potential for more covalent bonding with oxygen are expected to have lower $\mathrm{K}$ values (more FO than expected from stoichiometry), as nicely demonstrated by recent ${ }^{17} \mathrm{O}$ NMR on $\mathrm{PbO}-\mathrm{SiO}_{2}$ glasses, where $\mathrm{FO}$ is well-resolved even for silica contents well above the “orthosilicate" value [47], as well as by the presence of $\mathrm{FO}$ in crystalline $\mathrm{Pb}_{2} \mathrm{SiO}_{4}$ itself [48]. From these results, $\mathrm{K}$ values of about 30-60 can be estimated. Much higher $\mathrm{K}$ values are likely for systems with low field strength modifiers such as alkali cations, as supported by very low oxide ion activities derived from vapor pressure and electrochemical measurements [49]. 
Low K values are probably expected for systems such as silica-hafnia and silica-zirconia with a very high field strength modifier, as these reflect smaller energy differences among the oxygen species in reaction (3) due to strong Hf-O or Zr-O interactions that stabilize the "free" oxide ion species. A $K$ value of 1 would suggest a $\Delta G$ for the reaction of 0 , and, intriguingly, little or no effect of temperature on the species proportions. More typical values of $\mathrm{K}>1$ are consistent with $\Delta \mathrm{G}<0$ and a reduction in $\mathrm{K}$ and an increase in the formation of $\mathrm{FO}$ at higher temperature.

Another important variable related to the extent of reaction (3) and the value of $\mathrm{K}$ is the configurational entropy of mixing $\Delta \mathrm{S}_{\mathrm{mx}}$ of the oxygen species generated. The ideal value of $\Delta \mathrm{S}_{\mathrm{mx}}$ can be simply estimated from $\Sigma \mathrm{X}_{\mathrm{i}} \ln \mathrm{X}_{\mathrm{i}}$, where $\mathrm{X}_{\mathrm{i}}$ are the mole fractions, and is shown in Figure 6 as a function of $\mathrm{K}$ at several different silica contents. For all, the entropy is at a maximum for $\mathrm{K}=1$. This suggests that the materials studied here are near to a maximal state of disorder at least with respect to this aspect of the structure.

For a given composition on the $\mathrm{SiO}_{2}-\mathrm{HfO}_{2}$ or $\mathrm{SiO}_{2}-\mathrm{ZrO}_{2}$ binary and a value of $\mathrm{K}$, and the obvious assumptions that the concentrations of these three oxygen species sum to $100 \%$ and that their total formal charges must be balanced by $\mathrm{Hf}^{4+}$ or $\mathrm{Zr}^{4+}$, the oxygen speciation can be readily calculated. Figure 7 plots these curves for $\mathrm{K}=1$ and $\mathrm{K}=2$, as well as the straight line segments predicted by an infinite value for $\mathrm{K}$. Species distributions are symmetrical about the 50-50 composition because Si and $\mathrm{Hf}$ or $\mathrm{Zr}$ have the same valence; NBO increase in concentration, and $\mathrm{BO}$ and FO decrease, as K increases. Shown also are the oxygen species concentrations measured by ${ }^{17} \mathrm{O}$ NMR. Within experimental uncertainty, values for the $21 \%$ silica, $\mathrm{SiO}_{2}-\mathrm{HfO}_{2}$ IBS film and the $41 \%$ silica, $\mathrm{SiO}_{2}-\mathrm{ZrO}_{2}$ film, follow the same trends as those for the sol-gel materials, and all are closely bracketed by the $\mathrm{K}=1$ and $\mathrm{K}=2$ calculated curves. 


\subsection{Transient, metastable equilibrium states in thin-film oxides?}

This remarkable agreement between experimental speciation and a very simple thermodynamic model suggests again that the short-range structures of both the annealed sol gel materials and the IBS thin film result from a transient metastable equilibrium in a liquid-like state. The results of both synthesis pathways seem to pass through a time/temperature state where bond breaking is rapid enough to allow local re-equilibration, but diffusion is slow enough to prevent the formation of either crystals or the separation into domains of nearly pure silica and hafnia or zirconia as suggested by the predicted two-liquid solvus [19]. This state may simply be that of a highly supercooled single phase liquid at a temperature just above the glass transition. Glass transitions have not been observed or measured in such samples, but if present, might be somewhere near to 650 to $700{ }^{\circ} \mathrm{C}$ given the rapid crystallization at slightly higher temperatures,

We note, however, that at least the Si speciation (apart from a small concentration of what appear to be $\mathrm{SiO}_{5}$ groups) in the as-formed silica-hafnia IBS film is very similar to that of the film annealed at $600{ }^{\circ} \mathrm{C}$ during ${ }^{17} \mathrm{O}$ exchange, suggesting that the metastable equilibrium state was reached during deposition. It is possible, for example, that atomic and ionic species when arriving at the film surface have sufficient energy to allow for such local equilibration on short length and time scales, followed by rapid cooling through $\mathrm{T}_{\mathrm{g}}$. Again, it is intriguing to note that a K value near 1 for reaction (3) implies little effect of temperature (or of fictive temperature) on this aspect of the structure, suggesting that similar quenched structures might be observed for a wide range of cooling rates or initial thermal conditions. In other words, a system that is highly random near $\mathrm{T}_{\mathrm{g}}$ will not become much more random at higher $\mathrm{T}$. It is important to note that the 
extent of reaction (3) obviously does not capture all aspects of the ordering state or short-range speciation of the structure. For example, the small concentration of $\mathrm{SiO}_{5}$ groups in the unannealed silica-hafnia film is mostly removed by annealing, indicating that it has a relatively high energy of formation and is likely to increase at higher temperatures.

As noted above, a similar situation has been suggested to explain the remarkable similarity in the distributions of $\mathrm{AlO}_{4}, \mathrm{AlO}_{5}$, and $\mathrm{AlO}_{6}$ groups in thin films of alumina produced by a variety of synthesis routes, including ion beam sputtering, atomic layer deposition, and rf sputtering [21-23], at least in films thick enough to avoid effects of substrate and/or high surface to volume ratio [20]. Here, relatively small differences in speciation have been treated with a thermodynamic model including a temperature term resembling fictive $\mathrm{T}$ [21, 22]; again a state of metastable equilibrium may be implied, in this case with a structure drastically different from those of crystalline alumina. In recent ${ }^{17} \mathrm{O}$ NMR studies of $\mathrm{Ta}_{2} \mathrm{O}_{5}$ sol-gel and IBS films $[5,6]$, the close similarity of structures for the two synthesis routes again implied a common state of equilibrium. Furthermore, the observation that only small changes in structure were observed on comparing an IBS film annealed with ${ }^{17} \mathrm{O}_{2}$ gas after deposition, with a film initially deposited with ${ }^{17} \mathrm{O}_{2}$ gas without subsequent annealing, suggests again that enough thermal energy was present during deposition to reach a similar state. (In detail, some minor readjustment of structure, probably accompanying density relaxation and oxidation of minor amounts of lower valence Ta, was observed.) In two-component, $\mathrm{TiO}_{2}-\mathrm{Ta}_{2} \mathrm{O}_{5}$ sol-gel and IBS films (the latter of particular interest in the most recently developed mirrors for the LIGO interferometers), the two synthesis routes produced similar distributions of oxygen species with varying numbers of Ta and Ti neighbors, as observed by ${ }^{17} \mathrm{O}$ NMR [5, 50], again implying a comparable metastable 
state was reached. In the latter case, though, only samples annealed during ${ }^{17} \mathrm{O}$ exchange were examined.

\subsection{Extent of disorder}

The observation that $\mathrm{K}$ values near to 1 for the oxygen speciation in the silica-hafnia and silica-zirconia films accurately predict the observations may imply an unusually highly disordered state, again perhaps as expected for a silicate system with a tetravalent "modifier” (or “intermediate”) cation. In most conventional glass-forming liquids, corresponding K values are much higher, as noted above. Other aspects of the network structures of multicomponent silicate glasses are also often considerably more ordered than predicted by random models, for example distributions of bridging and non-bridging oxygens on Si species and between Si and Al species [51, 52], and of tetrahedral Al and Si in alkali and alkaline earth aluminosilicates [53, 54]. Higher field strength modifiers tend to increase the extent of disorder by stabilizing minor, higher energy species. The results described here for silica-hafnia and silica-zirconia may thus be among the most extreme known examples of this trend. If the observed oxygen species do indeed mix randomly in these non-network thin film materials, then this process would contribute to the ability of even 20-30 mole \% silica to stabilize the amorphous phase against crystallization and phase separation. This stability allows these materials to be useful in high-quality mirror coatings in optical systems, as a minimum level of a low atomic number “dopant” has a minimal reduction in the desirable high refractive index of the heavy metal oxide. Addition of other components could lead to further stabilization, as is well-known in "normal” glass-forming oxide liquids. 


\section{Conclusions}

In the silica-hafnia and silica-zirconia binary systems, ${ }^{17} \mathrm{O}$ NMR spectra show excellent resolution among resonances for oxygen ions coordinated only by $\mathrm{Hf}$ (or $\mathrm{Zr}$ ), by $\mathrm{Si}+\mathrm{Hf}$ (or $\mathrm{Zr}$ ), or by Si only in amorphous materials made by sol gel and ion beam sputtering methods.

Combined with ${ }^{29} \mathrm{Si}$ NMR, quantitative descriptions of the short-range structure can be obtained. As has been reported recently for other systems such as amorphous tantala, tantala-titania and alumina, structures are very similar for samples made by different methods, suggesting the possibility that transient states of metastable equilibrium are obtained during synthesis, possibly resembling those of deeply supercooled oxide liquids. A simple thermodynamic analysis in terms of well-known oxygen speciation reactions yields a consistent description of the amorphous $\mathrm{SiO}_{2}-\mathrm{Hf}(\mathrm{Zr}) \mathrm{O}_{2}$ system, indicating an unusually (but not unexpected) stability of the "free" oxide ion (no Si bonding) in compositions with very high field strength “modifier” cations. If such apparently “non-equilibrium” amorphous materials produced by thin film deposition methods do indeed pass through metastable, liquid-like states of equilibrium, then development and application of thermodynamic approaches to their structures, as has been done for many decades for conventional glasses formed from high temperature melts, has great potential in predictive models of property variation with composition and thermal history.

\section{Acknowledgements}

This research was supported by the National Science Foundation, grant number PHYS1068596 (Robert Byer, Dept. of Applied Physics, Stanford University, P.I.). We are grateful for 
many discussions with the Stanford LIGO team and for the efforts of colleagues at MLD Technologies. We especially thank Steven Penn (Dept. of Physics, Hobart and William Smith Colleges) for supplying the sputtered film samples, and Dr. Ian MacLaren (School of Physics and Astronomy, University of Glasgow), and two anonymous reviewers for helpful comments on the manuscript. 


\section{References}

[1] G. Harry, Class. Quant. Grav. 27 (2010) 084006.

[2] R. Bassiri, K. B. Borisenko, D. J. H. Cockayne, J. Hough, I. MacLaren and S. Rowan, Appl. Phys. Lett. 98 (2011) 031904.

[3] R. Bassiri, K. Evans, K. B. Borisenko, M. M. Fejer, J. Hough, I. MacLaren, I. W. Martin, R. Route and S. Rowan, Acta Mat. 61 (2013) 1070.

[4] R. Bassiri, et al., Appl. Phys. Lett. Mat. 3 (2015) 036103.

[5] N. Kim and J. F. Stebbins, Chem. Mater. 23 (2011) 3460.

[6] N. Kim and J. F. Stebbins, J. Non-Cryst. Solids 378 (2013) 158.

[7] G. M. Harry, et al., Class. Quant. Grav. 24 (2007) 405.

[8] I. W. Martin, et al., Class. Quant. Grav. 27 (2010) 225020.

[9] R. Hamdan, J. P. Trinastic and H. P. Cheng, J. Chem. Phys. 141 (2014) 054501.

[10] J. P. Trinastic, R. Hamdan, Y. Wu, L. Zhang and H. P. Cheng, J. Chem. Phys. 139 (2013) 154506.

[11] T. J. Bastow, M. E. Smith and H. J. Whitfield, J. Mater. Chem. 6 (1996) 1951.

[12] G. Mountjoy, R. Anderson, R. J. Newport and M. E. Smith, J. Phys.: Condens. Matter 12 (2000) 3505.

[13] G. Mountjoy, M. A. Holland, P. Gunawidjaja, G. W. Wallidge, D. M. Pickup, R. J. Newport and M. E. Smith, J. Sol-Gel Sci. Tech. 26 (2003) 161.

[14] L. Armelao, S. Gross, K. Müller, G. Pace, E. Tondello, O. Tsetsgee and A. Zattin, Chem. Mater. 18 (2006) 6019. 
[15] D. M. Pickup, G. Mountjoy, G. W. Wallidge, R. J. Newport and M. E. Smith, Phys. Chem. Chem. Phys. 1 (1999) 2527.

[16] P. J. Dirken, R. Dupree and M. E. Smith, J. Mater. Chem. 5 (1995) 1261.

[17] S. Ramanathan, P. C. McIntyre, J. Luning, P. S. Lysaght, Y. Yang, Z. Chen and S. Stemmer, J. Electrochm. Soc. 150 (2003) F173.

[18] S. Kohara, et al., Nature Comm. 5 (2014) 5892.

[19] H. Kim and P. C. McIntyre, J. Appl. Phys. 92 (2002) 5094.

[20] S. K. Lee and C. W. Ahn, Sci. Rep. 4 (2014) 4200.

[21] S. K. Lee, S. B. Lee, S. Y. Park, Y. S. Yi and C. W. Ahn, Phys. Rev. Let. 103 (2009) 095501.

[22] S. K. Lee, S. Y. Park, Y. S. Yi and J. Moon, J. Phys. Chem. C 114 (2010) 13890.

[23] N. Kim, R. Bassiri, M. M. Fejer and J. F. Stebbins, J. Non-Cryst. Solids 405 (2014) 1.

[24] K. J. D. MacKenzie and M. E. Smith, Multinuclear Solid-State NMR of Inorganic Materials (New York, Pergamon, 2002).

[25] R. D. Shannon and C. T. Prewitt, Acta Cryst. 25 (1969) 925.

[26] A. C. Palke and J. F. Stebbins, Am. Mineral. 96 (2011) 1090.

[27] A. C. Palke, J. F. Stebbins and L. A. Boatner, Inorg. Chem. 52 (2013) 12605.

[28] S. J. Gaudio, S. Sen and C. E. Lesher, Geochim. Cosmochim. Acta (2008) 1222.

[29] J. F. Stebbins and B. T. Poe, Geophys. Res. Lett. 26 (1999) 2521.

[30] X. Xue, J. F. Stebbins, M. Kanzaki, P. F. McMillan and B. Poe, Am. Mineral. 76 (1991) 8.

[31] J. F. Stebbins and P. McMillan, Am. Mineral. 74 (1989) 965.

[32] J. F. Stebbins, Nature 351 (1991) 638. 
[33] K. E. Kelsey, J. F. Stebbins, J. L. Mosenfelder and P. D. Asimow, Am. Mineral. 94 (2009) 1205.

[34] J. S. Hartman, A. Narayanan, S. S. Rigby, D. R. Sliwinski, N. M. Halden and A. D. Bain, Can. J. Chem. 85 (2007) 56.

[35] J. F. Stebbins, J. R. Smyth, W. R. Panero and D. J. Frost, Am. Mineral. 94 (2009) 905.

[36] L. M. Thompson, R. J. McCarty and J. F. Stebbins, J. Non-Cryst. Solids 358 (2012) 2999.

[37] L. M. Thompson and J. F. Stebbins, Am. Mineral. 96 (2011) 841.

[38] N. Kim, C.-H. Hsieh, H. Huang, F. B. Prinz and J. F. Stebbins, Sol. State Ionics 178 (2007) 1499.

[39] G. Lucovsky and G. B. Rayner, Jr., Appl. Phys. Lett. 77 (2000) 2912.

[40] W. Vogel, Glass Chemistry (Berlin, Springer-Verlag, 1994).

[41] J. F. Stebbins, N. Kim, M. J. Andrejcak, P. M. Boymel and B. K. Zoitos, J. Am. Ceram. Soc. 92 (2009) 68.

[42] A. K. Varshneya, Fundamentals of Inorganic Glasses (San Diego, CA, Academic Press, Inc., 1994).

[43] C. R. Masson, J. Iron Steel Inst. 210 (1972) 89.

[44] C. R. Masson, J. Non-Cryst. Solids 25 (1977) 3.

[45] S. Sen and J. Tangeman, Am. Mineral. 93 (2008) 946.

[46] N. K. Nasikas, T. G. Edwards, S. Sen and G. N. Papatheodorou, J. Phys. Chem. B 116 (2012) 2696.

[47] S. K. Lee and E. J. Kim, J. Phys. Chem. C 119 (2014) 748.

[48] L. S. Dent Glaser, R. A. Howie and R. M. Smart, Acta Cryst. B 37 (1981) 303. 
[49] S. Abdelouhab, R. Podor, C. Rapin, M. J. Toplis, P. Berthoud and M. Vilasi, J. Non-Cryst. Solids 354 (2008) 3001.

[50] N. Kim, J.F. Stebbins, LIGO-Virgo Collaboration Meeting, Bethesda, MD, March 2013 (2013).

[51] J. R. Allwardt, S. K. Lee and J. F. Stebbins, Am. Mineral. 88 (2003) 949.

[52] B. O. Mysen and P. Richet, Silicate Glasses and Melts, Properties and Structure (Amsterdam, Elsevier, 2005).

[53] S. K. Lee and J. F. Stebbins, Am. Mineral. 84 (1999) 937.

[54] S. K. Lee and J. F. Stebbins, J. Phys. Chem. B 104 (2000) 4091. 
Table 1. Centers of gravity for ${ }^{29}$ Si MAS NMR peaks for amorphous silica-hafnia and silicazirconia materials.

\begin{tabular}{lllllll}
\hline $\begin{array}{l}\text { silica } \\
\text { contents* }\end{array}$ & $\mathbf{1 2 \%}$ & $\mathbf{3 1 \%}$ & $\mathbf{5 4 \%}$ & $\mathbf{1 0 0 \%}$ & $\begin{array}{l}\mathbf{2 1 \%} \\
\text { (Hf film) }\end{array}$ & $\begin{array}{l}\mathbf{4 1 \%} \\
\text { (Zr film) }\end{array}$ \\
\hline $\begin{array}{l}\text { un-heated } \\
( \pm 0.5 \mathrm{ppm})\end{array}$ & -81 & -85.4 & -89.5 & $\begin{array}{l}-110.6 \\
-101.5\end{array}$ & -85.9 & -94 \\
& & & & -92.1 & & \\
& & & & & & \\
$\mathbf{6 0 0}^{\circ} \mathbf{C}$ & -83.5 & -89.3 & -94.4 & -111.8 & -87.3 & -96 \\
$( \pm 0.5 \mathrm{ppm})$ & & & & & & \\
\hline$*$ Silica & & & & & \\
\hline
\end{tabular}

*Silica contents based on analysis of ${ }^{17} \mathrm{O}$ NMR spectra (see Table 2 and text). 
Table 2. Relative peak areas (in \%) in ${ }^{17} \mathrm{O}$ MAS NMR spectra for silica-hafnia and silica-zirconia materials. In peak labels, " $\mathrm{M}$ " denotes $\mathrm{Hf}$ or $\mathrm{Zr}$. When crystalline $\mathrm{HfO}_{2}$ was observed, total peak area (crystal plus amorphous) is reported on the first line (as used to estimate bulk composition); area of amorphous component is on second line.

\begin{tabular}{|c|c|c|c|c|c|c|}
\hline $\begin{array}{l}\mathrm{O}_{\mathrm{SiO}} \mathrm{SiO}_{2} \\
\text { nominal }\end{array}$ & $\begin{array}{c}\% \\
\mathrm{SiO}_{2} \text {, } \\
\text { calc.* }\end{array}$ & OM3 & OM4 & Si-O-M2 & Si-O-Si & $Q^{4}, \max ^{* *}$ \\
\hline \multicolumn{7}{|l|}{ sol-gel } \\
\hline $\mathbf{5 0}$ & 54 & 20.0 & 6.0 & 36.0 & 38.0 & 68 \\
\hline 30 (total) & 31 & 38.5 & 13.0 & 32.5 & 16.0 & \\
\hline (am.) & & 39.0 & 12.0 & 33.0 & 16.0 & 49 \\
\hline 12 (total) & 12 & 55.0 & 24.5 & 17.0 & 3.5 & \\
\hline (am.) & & 53.5 & 23.5 & 19.0 & 4.0 & 30 \\
\hline \multicolumn{7}{|l|}{ Hf film } \\
\hline 30 & 21 & 47.0 & 15.5 & 31.5 & 6 & 28 \\
\hline \multicolumn{7}{|l|}{ Zr film } \\
\hline 25 & 41 & 30.0 & 7.0 & 38.0 & 25.0 & 57 \\
\hline
\end{tabular}

* Based on oxygen speciation, see text.

** Maximum fraction of $\mathrm{Si}$ in $\mathrm{Q}^{4}$ groups, if all S-O-Si were in silica-like regions. As noted in the text, these values are far above those allowed by ${ }^{29} \mathrm{Si}$ spectra.

Estimated errors in oxygen species proportions are about $\pm 2 \%$ due to uncertainties in baselines and slight overlaps. Table entries are reported to nearest $0.5 \%$. 


\section{Figure captions}

Figure 1. Powder X-ray diffraction data for sol-gel materials annealed at $600{ }^{\circ} \mathrm{C}$.

Figure $2 .{ }^{29} \mathrm{Si}$ MAS spectra for sol-gel silica-hafnia materials, annealed at $600{ }^{\circ} \mathrm{C}$. The unheated, as-formed pure silica "gel” is shown for comparison. The location of the $\mathrm{Q}^{0}$ peak is based on that for crystalline zircon $\left(\mathrm{ZrSiO}_{4}\right) . \mathrm{Mol} \% \mathrm{SiO}_{2}$ is labeled.

Figure $3 .{ }^{29} \mathrm{Si}$ MAS spectra for the silica-hafnia IBS film with about $21 \% \mathrm{SiO}_{2}$, and of the silicazirconia IBS film with about $41 \% \mathrm{SiO}_{2}$, comparing as-deposited with that annealed at $600{ }^{\circ} \mathrm{C}$

during ${ }^{17} \mathrm{O}$ exchange. "R” marks a small rotor background signal, probably from $\mathrm{Mg}_{2} \mathrm{SiO}_{4}$. The vertical scale in the uppermost spectrum is multiplied by 5 relative to the others.

Figure $4 .{ }^{29}$ Si NMR magnetization (signal intensity relative to that of fully relaxed signal) as a function of relaxation delay for the $21 \% \mathrm{SiO}_{2}$ IBS film, showing effect of annealing.

Figure 5. ${ }^{17} \mathrm{O}$ MAS NMR spectra for $\mathrm{SiO}_{2}-\mathrm{HfO}_{2}$ and $\mathrm{SiO}_{2}-\mathrm{ZrO}_{2}$ IBS films, $\mathrm{SiO}_{2}-\mathrm{HfO}_{2}$ sol-gel materials, and crystalline monoclinic $\mathrm{HfO}_{2}$. The sol-gel and film samples were annealed at 600 ${ }^{\circ}$ C. Asterisks mark spinning sidebands, and “?” labels a tiny signal from an unknown impurity. $\mathrm{Mol} \% \mathrm{SiO}_{2}$ is labeled. 
Figure 6. Calculated ideal configurational entropy of mixing for oxygen speciation derived from reaction (3) as a function of the apparent equilibrium constant $\mathrm{K}$, plotted on a $\log _{10}$ scale. Curves for three different mole percentages of silica are shown.

Figure 7. Mole \% of oxygen species, with "free” oxide (FO, red), non-bridging oxygen (NBO, blue), and bridging oxygen (BO, black) calculated from reaction (3) for $\mathrm{K}=1$ (solid curves), $\mathrm{K}=2$ (dashed curves), and $\mathrm{K}=\infty$ (straight line segments). Data from ${ }^{17} \mathrm{O}$ NMR spectra are shown by triangles for FO, circles for NBO, and squares for BO. Open symbols are for sol-gel materials, closed symbols for IBS films, silica-hafnia at $21 \% \mathrm{SiO}_{2}$ and silica-zirconia at $41 \% \mathrm{SiO}_{2}$. 

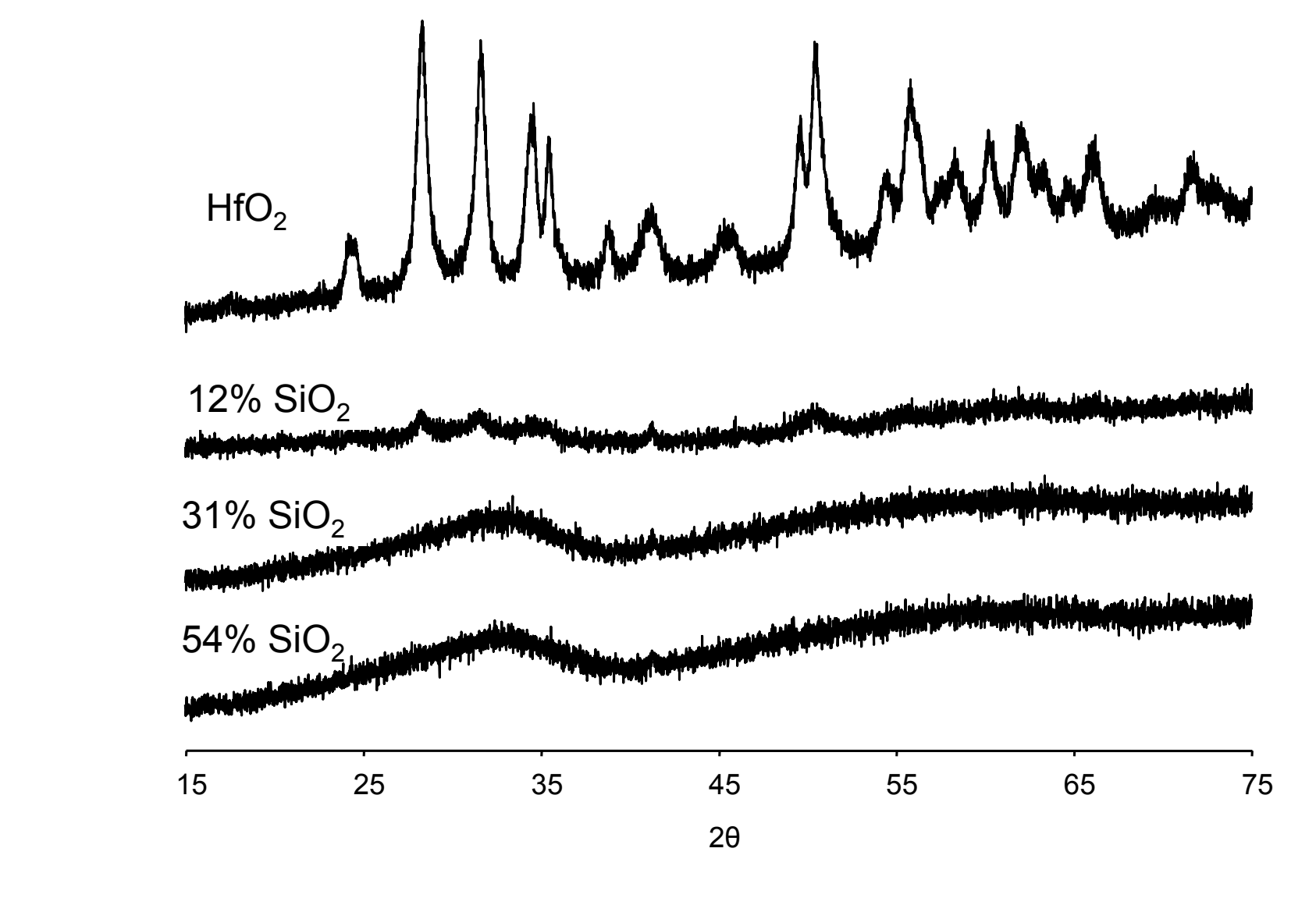

Figure

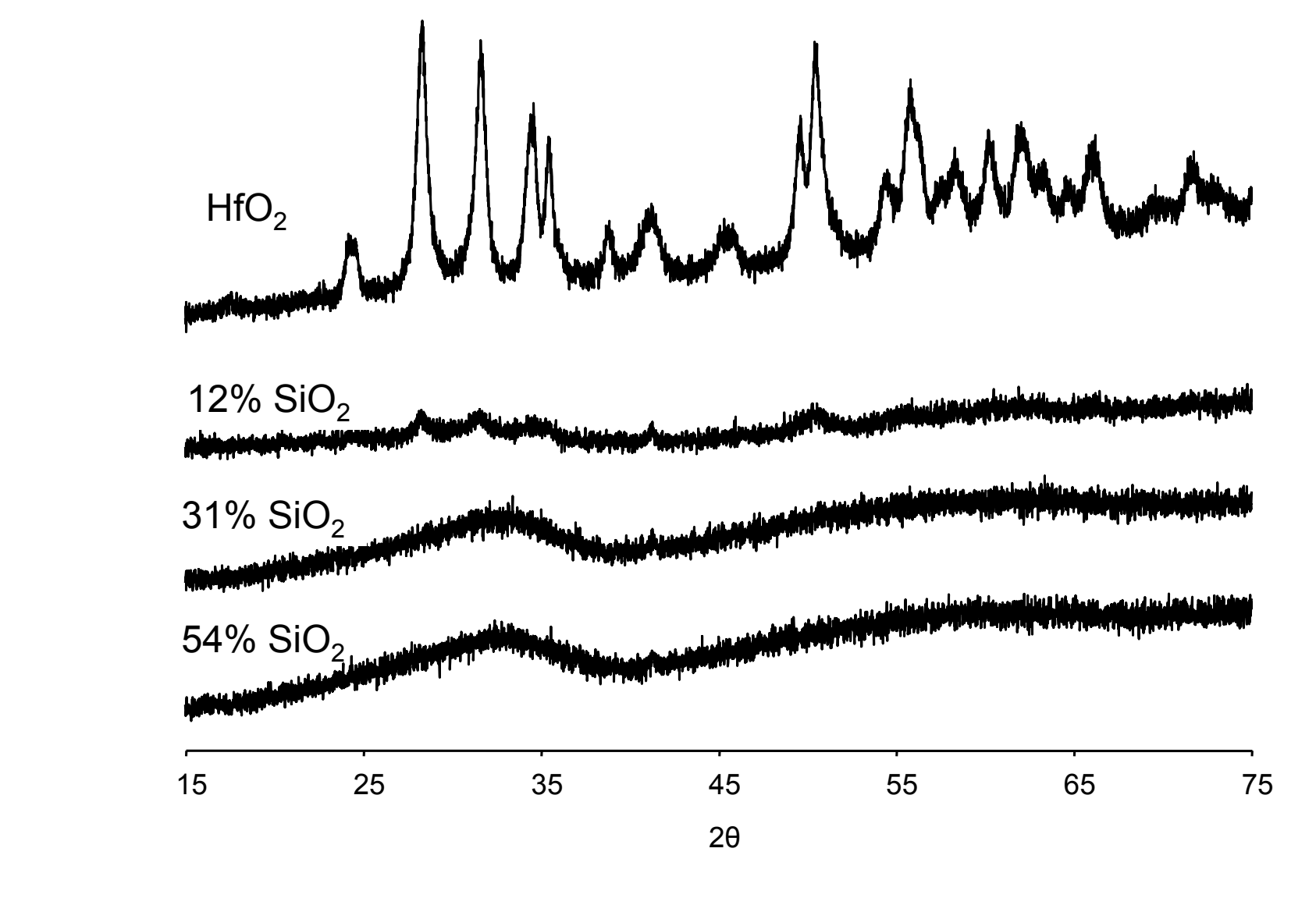

\section{Figure}

.

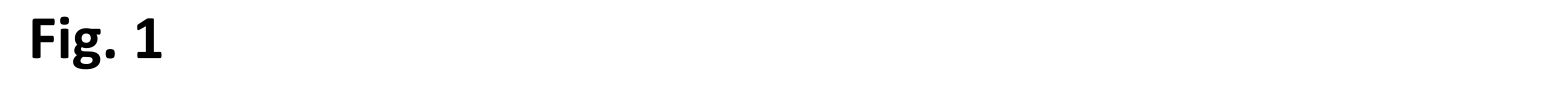

Fig. 1
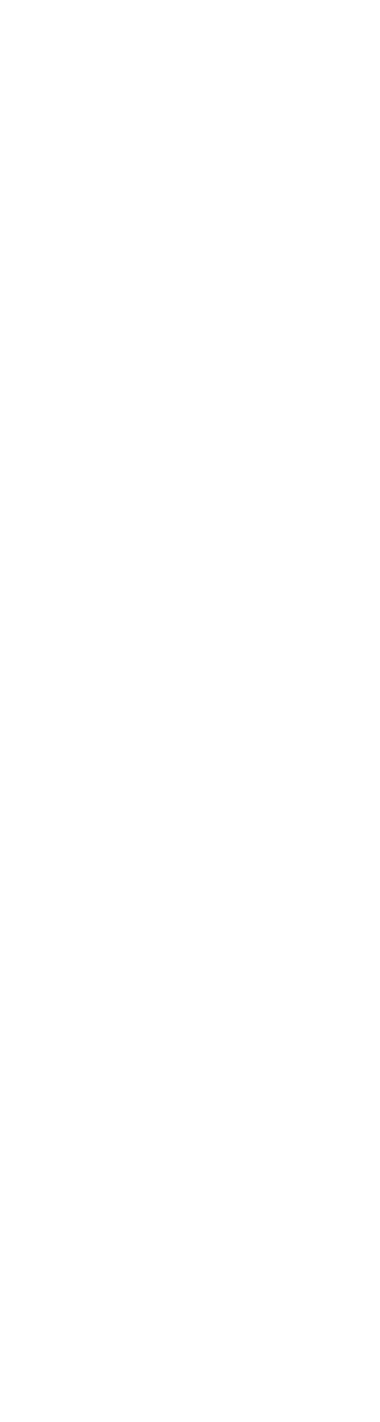

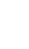


Fig. 2

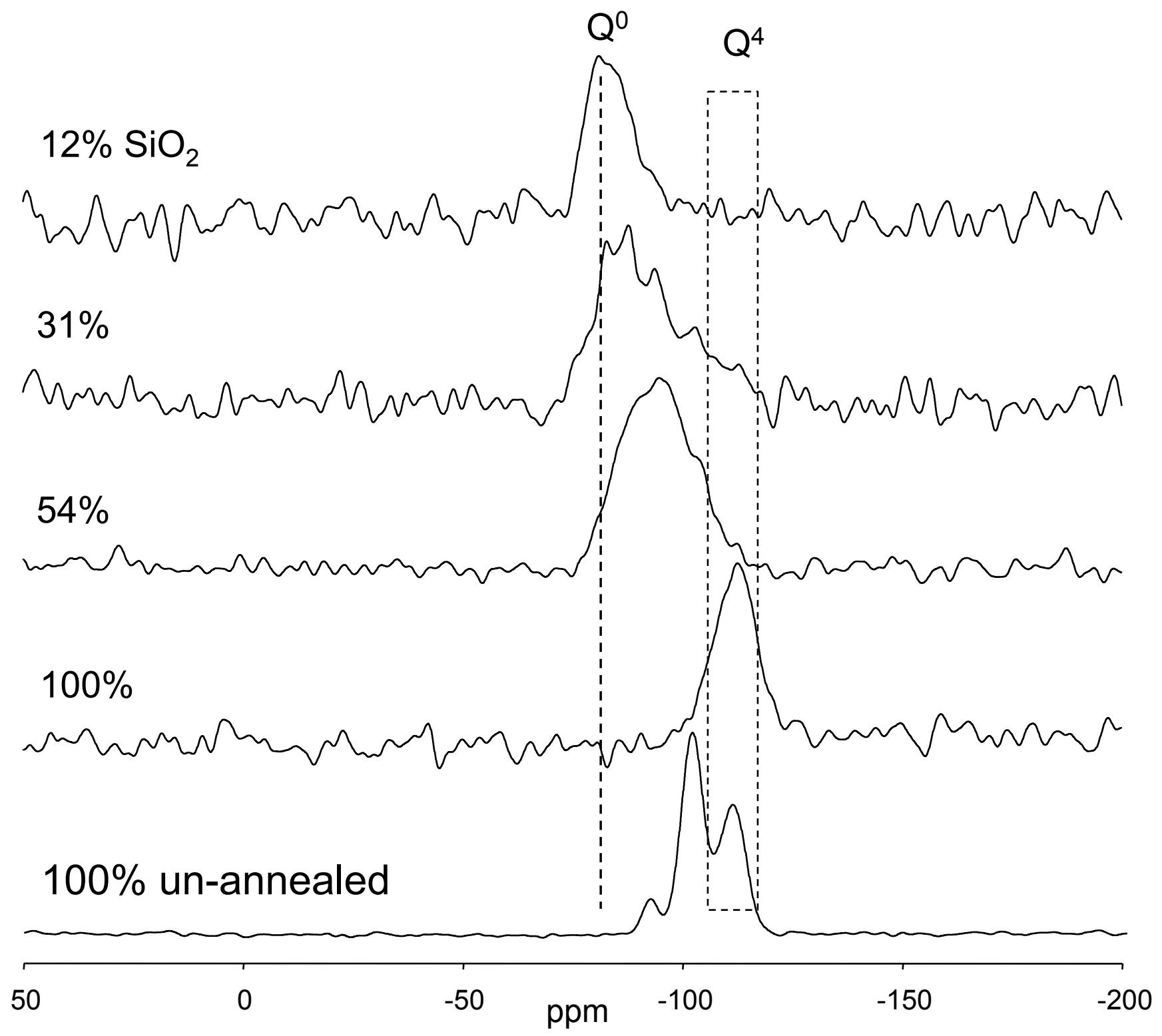


Fig. 3

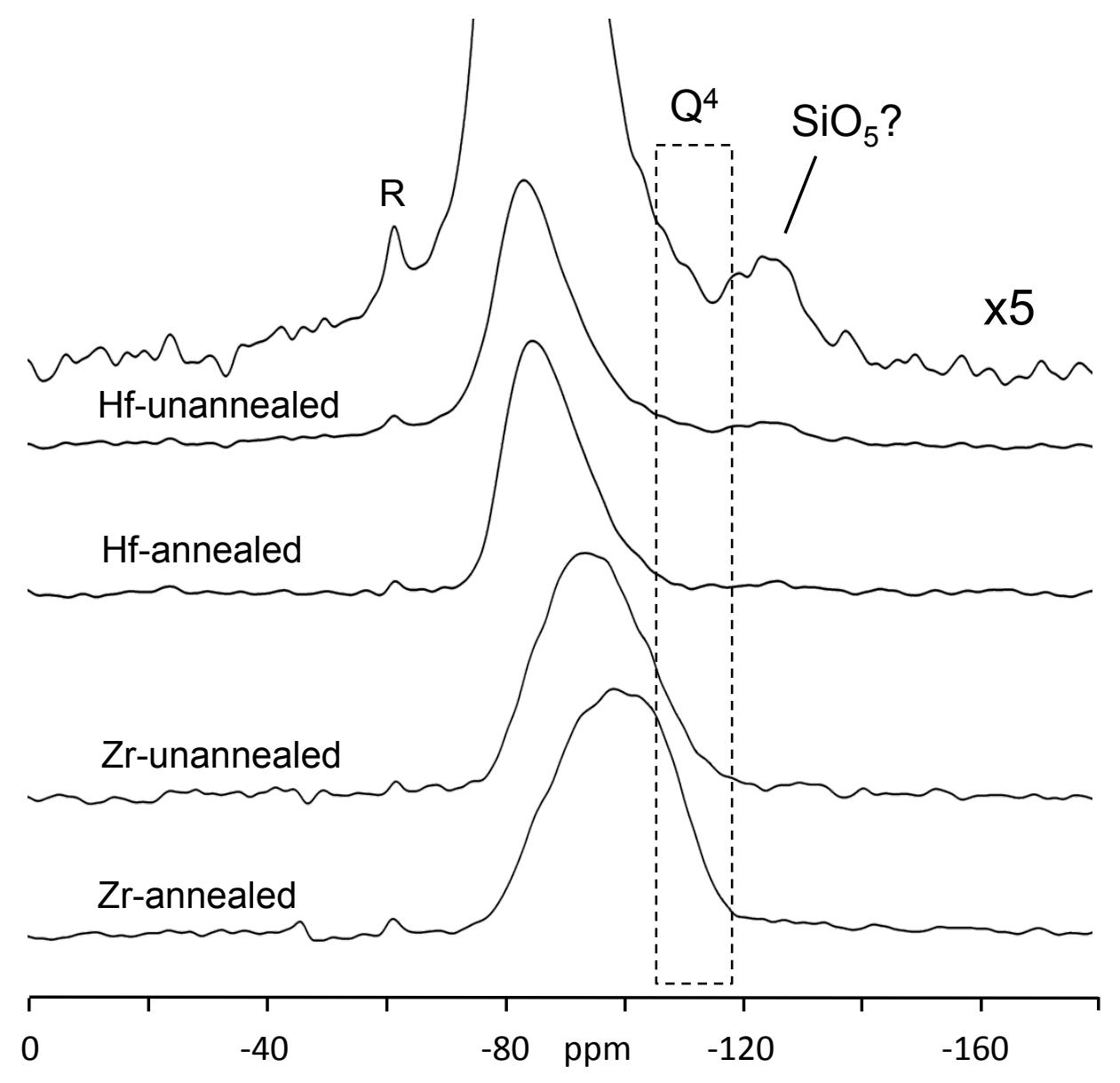


Fig. 4

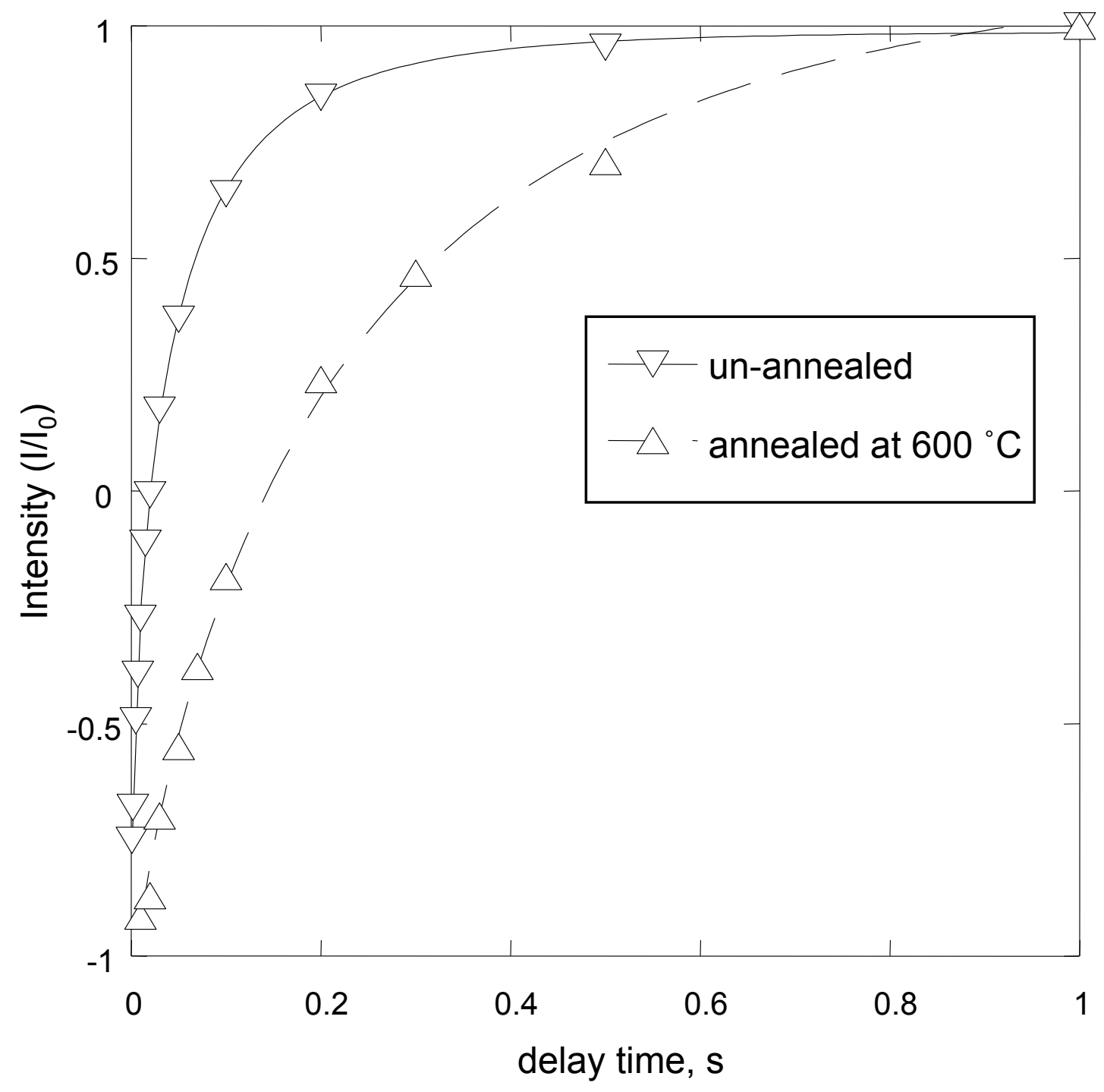


Fig. 5

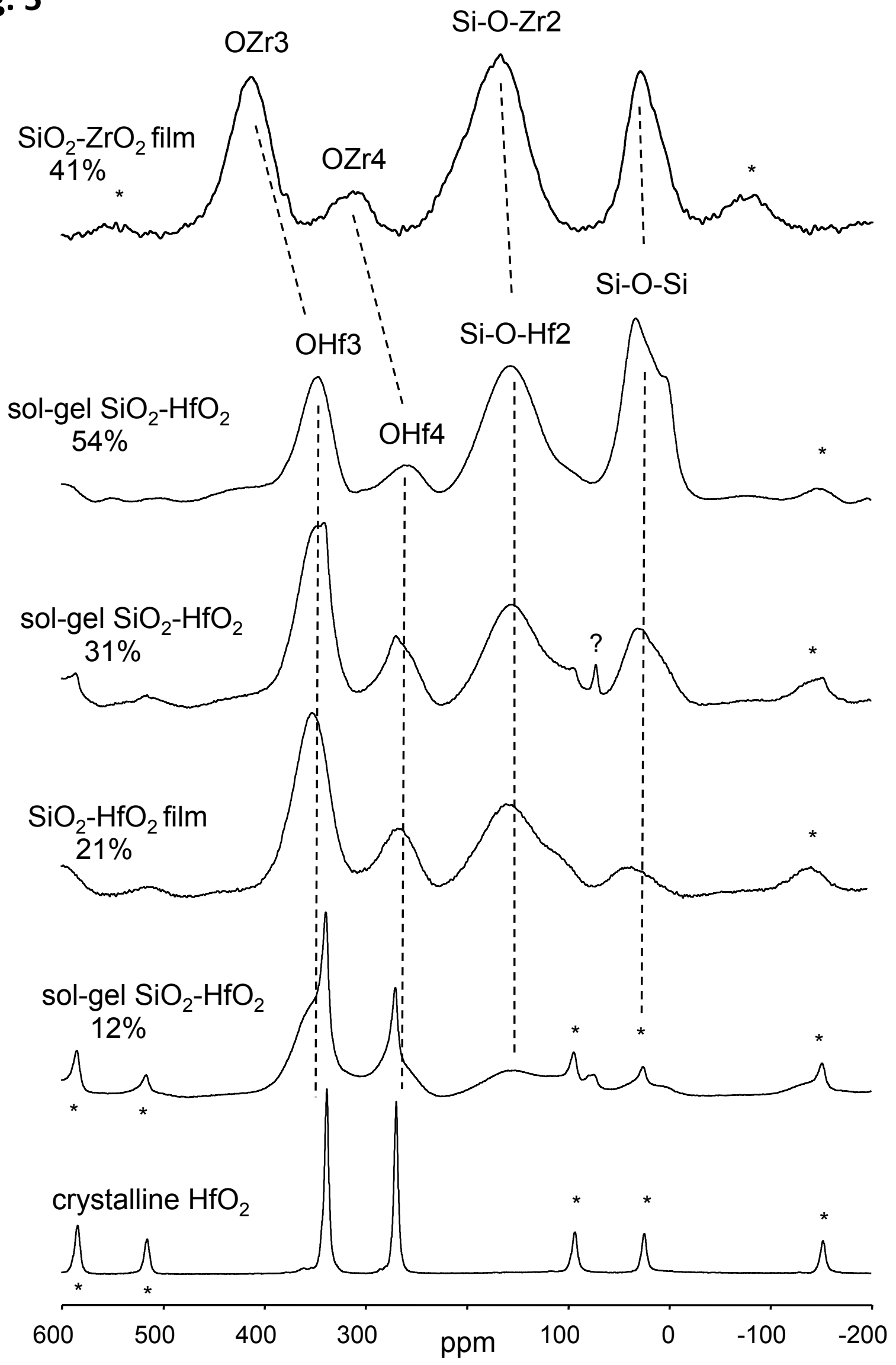


Fig. 6

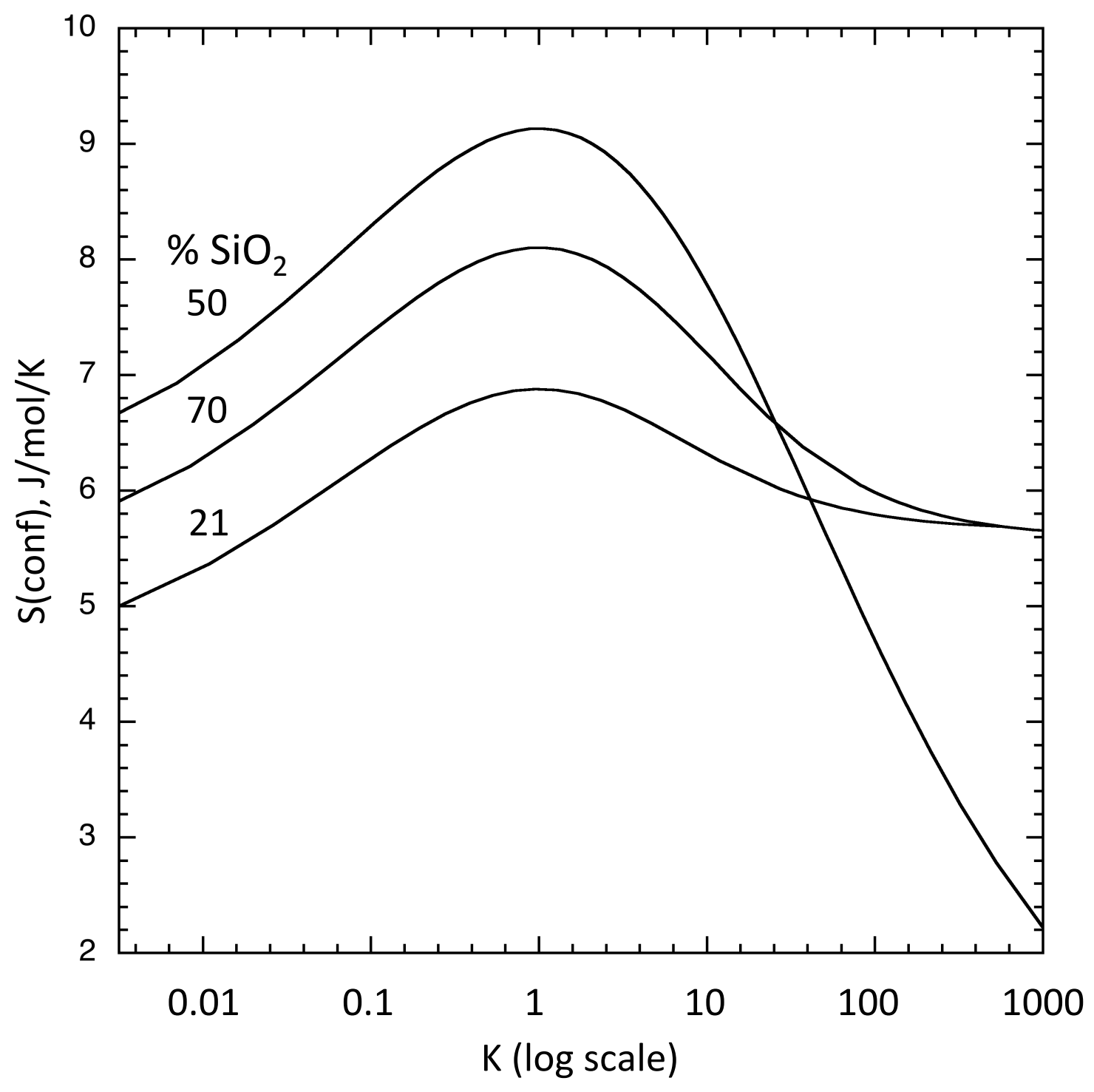


Fig. 7-revised with color

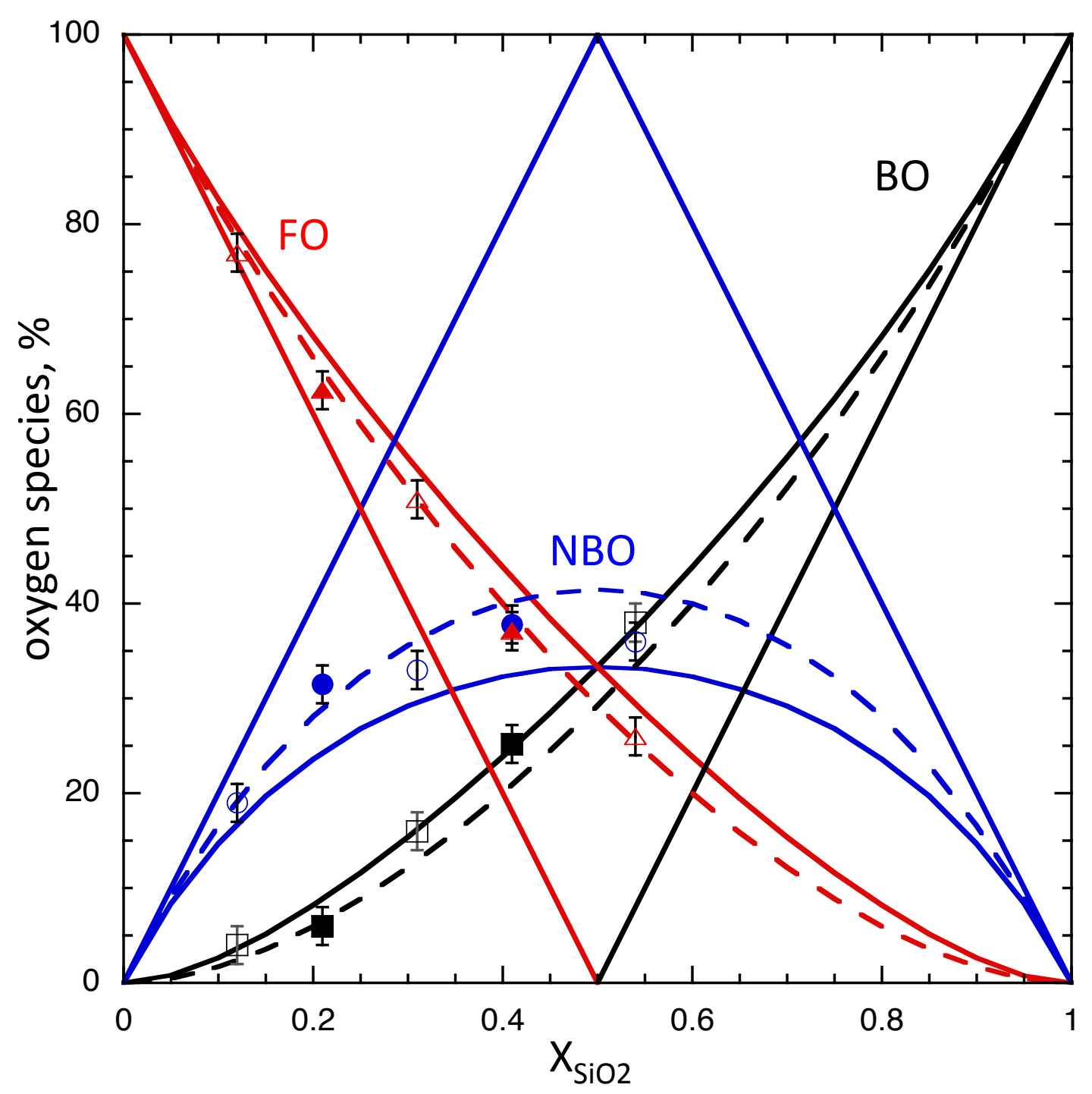

